\title{
V PLENÁRIA DA INDÚSTRIA E COMÉRCIO: LÓCUS DE DISCUSSÃO SOBRE A AÇÃO POLÍTICA DO EMPRESARIADO FLUMINENSE
}

\author{
JÚLIO CÉZAR OLIVEIRA DE SOUZA ${ }^{1}$
}

\begin{abstract}
Resumo
A V Plenária da Indústria e Comércio (PLENINCO) reuniu empresários de vários segmentos econômicos no estado do Rio de Janeiro. Os objetivos dessa plenária seriam perseguidos durante todo o governo Collor, o que se desdobraria em uma aliança de ocasião entre empresários fluminenses e o presidente da República até seu afastamento, em setembro de 1992. É necessário ressaltar que essa aproximação ocorria por meio de uma relação simbiótica, na qual o governo federal facilitaria a entrada de investimentos no estado, destarte acabando com esvaziamento econômico da região, e, em contrapartida, ganharia o apoio político do estado e visibilidade nacional. Essa conjuntura é objeto de análise a partir do delineamento dos projetos de desenvolvimento econômico orquestrados por esse empresariado.
\end{abstract}

Palavras-chave: v PLENINCO; empresariado; indústria; ciência e tecnologia

\begin{abstract}
The V PLENINCO brought together businessmen from various economic segments in the state of Rio de Janeiro. The objectives of this plenary would be persecuted throughout the Collor government, which would unfold in an alliance of opportunity between Fluminense entrepreneurs and the President until his retirement in September 1992. It should be emphasized that this approach occurred through a relationship symbiotic, in which the federal government would facilitate the entry of investments in the state, Thus ending economic emptying of the region, and in return, would gain the political support of the state and national visibility. This situation is the object of analysis from the design of economic development projects orchestrated by this business sector.
\end{abstract}

Keywords: v PLENINCO; business community; industrial; science and technology

\section{INTRODUÇÃO}

O presente artigo analisa o delineamento de projetos de desenvolvimento econômico, orquestrados na v PLENINCO, que reuniu empresários de vários segmentos econômicos no estado do Rio de Janeiro. Os objetivos dessa plenária seriam perseguidos durante todo o governo Collor, signo de uma transição de modelo de acumulação do capital, desdobrando-se em uma aliança de ocasião entre empresários fluminenses e o presidente da República até seu afastamento, em setembro de 1992. Ressaltamos que essa aproximação ocorria por meio de uma relação simbiótica, na qual o governo federal facilitaria a entrada de investimentos no estado, destarte acabando com esvaziamento econômico da região, e, em contrapartida, ganharia o apoio político do estado e visibilidade nacional. A ação desse empresariado tinha o objetivo de manter o status quo por meio de uma dinâmica engendrada entre capital e governo.

\section{UMA AGENDA NEOLIBERAL PARA O BRASIL A PARTIR DA CRISE FINANCEIRA}

Na segunda metade da década de 1970, entra em crise o regime de Bretton Woods, orquestrado em 1944 com objetivo de resolver problemas críticos do sistema financeiro internacional. A exaustão

1 Doutorando e Mestre em História Social pela Faculdade de Formação de Professores da Universidade do Estado do Rio de Janeiro. cezar1707@gmail.com 
desse ciclo de prosperidade do capital teria como indicadores a desaceleração do crescimento dos países industrializados, o que impactaria no comércio internacional, no aumento da inflação e na elevação de taxas de juros (Carneiro, 2002, p. 48).

O cerne do problema estava no sistema de câmbio fixo e na restrição à mobilidade de capitais. No plano internacional, havia o questionamento das nações centrais sobre a capacidade dos EUA de manter o ritmo de importações e investimentos externos e ainda garantir ouro para lastrear o dólar. Como desdobramento da questão, a alternativa encontrada foi a desregulamentação financeira, com a ampliação do circuito financeiro denominado em dólar para além do território americano (Carneiro, 2002, p. 52). Assim, deu-se a expansão do euromercado, importante fomentador de crédito internacional. Grande parte de seus financiamentos destinaram-se à cobertura de déficits de contas correntes dos países periféricos, entre eles o Brasil, o qual optara pela preservação do crescimento, ampliação e diversificação da estrutura produtiva.

Contudo, em 1979, os países endividados com juros baixos sofreriam uma guinada significativa em suas contas. Paul Volcker, então presidente do Federal Reserve, estabeleceu um choque de juros, elevando a taxa de juros dos títulos americanos a um patamar de $20 \%$. A ação secou a liquidez do mercado financeiro, haja vista a segurança e rentabilidade na compra de títulos do Tesouro Americano. Essa catalisação de capital para os EUA inaugurou uma nova fase do capitalismo internacional, a do dólar flexível. Dado o aumento dos juros no mercado financeiro, os países que rolavam suas dívidas como estratégia de crescimento econômico perderam sua capacidade de pagamento, $\mathrm{o}$ resultado foi a moratória de México e Brasil na década de 1980 (Lourenço Neto, 2013, p. 8).

O epicentro da crise do estado desenvolvimentista residiu na incapacidade de pagamento da dívida externa no início da década de 1980 (Sallum Júnior, 2003, p. 36). Ainda nesta década, houve a ampliação da dívida pública americana por causa de seus déficits orçamentário e comercial. Tal endividamento serviu de assentamento para o processo de securitização, pois os créditos desvalorizados dos países em desenvolvimento foram substituídos pelos títulos do Tesouro dos EUA, dotados de grande liquidez, assim fortalecendo o dólar. Em síntese, a evolução da crise do sistema de crédito internacional, associada à reimposição da supremacia do dólar, criou novas formas de intermediação financeira por meio da supremacia do mercado de capitais em substituição à dominância anterior do sistema de crédito comandado pelos bancos (Belluzzo, 2012, p. 104).

Isso evidenciou a necessidade de mudança no caráter do padrão de acumulação de capital, engendrando a necessidade de um rearranjo da articulação da classe empresarial com a nova perspectiva, $o$ neoliberalismo. Estatismo, nacionalismo e intervencionismo foram percebidos como manifestações de uma fase ultrapassada. A modernidade viria a reboque pela trilogia mercado, livre iniciativa e internacionalismo (Diniz, 2000, p. 59). Com efeito, a sociedade, as orientações ideológicas e a ordem política de diferentes países foram impactadas por esse novo arranjo econômico, que se aprofunda na década de 1990 (Diniz, 2007, p. 21).

$\mathrm{Na}$ esteira dessas transformações, o governo Collor representou um ponto de inflexão, com a redefinição de uma agenda pública, centrada na estabilização econômica e no desencadeamento das reformas estruturais, cuja materialização foi o Plano Collor I, norteado pelo combate à inflação e para destruição dos pilares do modelo estadista-desenvolvimentista (Diniz, 2000, p.101). O plano econômico permeava a política de rendas, finanças públicas, reforma do Estado, política cambial e monetária. Com um perfil de forte centralização política, a gestão de Collor seria caracterizada por uma modernização conservadora, um capitalismo autoritário e pela exclusão social (Vianna, 1991, p. 23).

\section{OBJETIVOS DA PLENÁRIA E SEUS PATROCINADORES}

A quinta reunião plenária do empresariado do estado do Rio de Janeiro, v PLENINCO, ocorreu em 25 de janeiro de 1990, quase dois meses antes da posse de Fernando Collor de Mello na Presidência da República. Seu objetivo precípuo foi o de instituir proposições que abarcavam interesses desse grupo e discutir formas de ação política para consolidá-los dentro de uma perspectiva regional.

$\mathrm{Na}$ introdução do documento que consolidara a plenária, expõem-se uma expectativa de uma nova era, a qual viria ratificar a transição democrática no Brasil. Nesse sentido, ante às expectativas positivas por parte desse grupo de empresários fluminenses, a ação deveria ser prioritariamente po- 
lítica, harmonizando-se com a nova postura da comunidade e em consonância com as aspirações gerais da nação, na busca do desenvolvimento econômico e social, com estabilidade, austeridade, eficiência e modernidade. A v PLENINCo também debateu sobre o papel mais ativo do empresariado no cenário político nacional, porém, sem perder de vista as conquistas dos grandes projetos de investimentos e de reformas no Rio de Janeiro (Firjan, 1990, p. 5).

Patrocinaram a V PLENinCo as seguintes entidades empresariais: Associação Comercial do Rio de Janeiro (ACRJ); Associação dos Dirigentes de Empresas do Mercado Imobiliário (ADEMI); Bolsa de Valores do Rio de Janeiro (BVRJ); Clube de Diretores Lojistas do Rio de Janeiro (CDLRJ); Federação das Associações Comerciais, Industriais e Agropastoris no Estado do Rio de Janeiro (Faciarj); Federação do Comércio Atacadista no Estado do Rio de Janeiro (FCARJ); Federação do Comércio Varejista no Estado do Rio de Janeiro (FCVRJ); Sindicato das Empresas de Seguros Privados e Capitalização no Estado do Rio de Janeiro (SERJ); Sociedade Nacional de Agricultura (SNA); Centro Industrial do Rio de Janeiro (CIRJ) e Federação das Indústrias do Estado do Rio de Janeiro (Firjan) (Firjan, 1990, p.7).

Como patrocinadores especiais da plenária estavam o Banco do Estado do Rio de Janeiro (Banerj), a Associação Nacional das Instituições do Mercado Aberto (Andima) e o Instituto Brasileiro de Executivos Financeiros (Ibef). Este último, criado em 1971 na cidade do Rio de Janeiro, é uma entidade sem fins lucrativos, que congrega executivos e empresários, com objetivo de realizar pesquisas, estudos e projetos em diversos segmentos da economia (Ibef, 2014). Já a Andima, era uma entidade civil sem fins lucrativos e de caráter privado com sede na cidade do Rio de Janeiro. Seu objetivo precípuo é o de contribuir para o desenvolvimento de mercados que ofereçam oportunidades de negócios a instituições financeiras, aos investidores e às empresas em geral. Esta associação reúne bancos comerciais, múltiplos e de investimento, corretoras, distribuidoras de valores e sociedades de crédito e financiamento. Seu modelo de funcionamento tem como principal característica a segurança na liquidação financeira e na custódia dos títulos negociados no mercado financeiro (Foregom, 2014). O Banerj, resultante da fusão entre o Banco do Estado da Guanabara (BEG) e o Banco do Estado do Rio de Janeiro (BERJ) em 1974, era o agente financeiro para projetos do governo do estado do Rio de Janeiro (A AFB, 2014). O banco foi o braço estatal presente na plenária. Sobre este ponto, fica evidente que a intervenção estatal refutada pelos empresários não era de todo verdadeira. O financiamento estatal para reproduzir o capital privado, ainda era um mecanismo utilizado pela iniciativa privada.

Participou como apoiadora especial do evento a Agência de Desenvolvimento Econômico do Estado do Rio de Janeiro (AD-RIO). Fundada 1987, com sede no Rio de Janeiro, a agência é reconhecida pelo Governo Estadual como de utilidade pública, conforme o Decreto no 10.942 , de 27/o1/88. Seu objetivo é a promoção do desenvolvimento econômico, social e cultural do Estado do Rio de Janeiro. Dentro da organização da estratégia de promoção investimentos, cabe a esta agência a elaboração de estudos de pré-viabilidade, de tendências e vocações de mercado e regionais, além de estudos setoriais que forneçam subsídios a empresas e investidores. A busca de parcerias, tanto técnicas quanto financeiras, para o desenvolvimento dos trabalhos é outro foco que orienta a atuação desta instituição. Entre seus associados fundadores estão bancos, empresas transnacionais e de capital nacional (AD-RIO, 2014).

\section{A DEFESA DO DESENVOLVIMENTO ECONÔMICO DO ESTADO DO RIO DE JANEIRO}

O modo de ação do empresariado fora impactado pela abertura política e pelo esgotamento do modelo desenvolvimentista. O executivo era o lócus privilegiado de discussão das demandas da classe empresarial e perdurou, sob esse viés de acumulação de capital, até o final da década de 1970. Seus desdobramentos foram a marginalização da mediação partidária, a fragmentação de articulação de demandas, a falta de negociação interclasses (entre empresários e trabalhadores) e a perspectiva de resolução de interesses de curto prazo, excluindo projetos de médio e longo prazo. Como exemplo ilustrativo dessa dinâmica de articulação com o Estado, temos a Confederação Nacional da Indústria (CNI) e a Firjan, cujos papéis de organismos de representação da indústria foram mitigados durante o regime militar. Neste período, foi estabelecida uma relação direta entre empresário e governo, sem, contudo, eliminar o sistema corporativo (Leopoldi, 200o, p. 300). Em síntese, o empresariado definiu sua identidade e seu perfil enquanto ator político fora da arena parlamentar-partidária, desenvolvendo um estilo de ação tópico, calcado na defesa de interesses particulares e de curto prazo (Diniz, 1992, p. 2). 
Com o advento do pluralismo representativo erigido na década de 1980, a estrutura de representação de interesses empresariais foi levada a um nível maior de complexidade, no qual novas entidades surgiram, como Instituto de Estudos para o Desenvolvimento Industrial (IEDI), Pensamento Nacional das Bases Empresariais (PNBE) e os institutos liberais (do Rio de Janeiro, São Paulo e Rio Grande do Sul). Essas entidades questionavam as velhas lideranças empresariais e, concomitantemente, formulavam propostas globais, as quais tinham o fim de ir além dos interesses setoriais.

É nessa nova conjuntura que foi realizada a v PLENiNCO. Sua organização tangenciava vários segmentos de interesses do capital com o objetivo de configurar o desenvolvimento econômico da região do Rio de Janeiro, tendo em vista interesses de curto, médio e longo prazos num cenário de recessão econômica. A participação de organizações empresariais ligadas ao mercado financeiro, comércio, indústria e agricultura com interesses articulados, em prol de projetos de desenvolvimento econômico, denota um posicionamento diferente daquele exercido num modelo corporativista. As proposições da plenária também evidenciavam a necessidade de aproximação com a arena política parlamentar, que serviria de canal de comunicação entre os empresários e o Estado, após a abertura política.

Haja vista a recessão econômica pela qual passava o Brasil desde a década de 1980, cuja influência foi determinante na perda de espaço do Rio de Janeiro no cenário nacional, avaliamos que a $\mathrm{V}$ PLENINCO concebe a ideia de defesa da coerência estruturada (Harvey, 2005, p. 146) como maneira de superar a crise capitalista em voga.

A anulação do espaço como barreira à reprodução do capital é concebida por meio da urbanização, a qual funciona como resposta capitalista específica à necessidade de eliminar custos e tempo de movimento sob condições de conexão interindústrias, de divisão social do trabalho e de necessidade de acesso à mão de obra e a consumidores finais.

Como desdobramento do processo de urbanização, a coerência estruturada abrange as formas e as tecnologias de produção, as quantidades e qualidades de consumo (padrão e estilo de vida de trabalhadores e burguesia), os padrões de demanda e oferta de mão de obra (hierarquias das habilidades de mão de obra e processos sociais de reprodução, para assegurar a oferta dos mesmos) e infraestruturas físicas e sociais na configuração de um território. Desta maneira, produção e consumo, luta de classes e a acumulação, a cultura e o estilo de vida definem o espaço regional (Harvey, 2005, p. 146).

Nesse sentido, no intento de manter seu status quo, as instituições de representação empresarial fluminense traçaram projetos de modo a adaptar-se às transformações de escala mundial, as quais poderiam solapar a coerência estruturada no território do Rio de Janeiro. Para tanto, debateram e chegaram a um consenso sobre as seguintes questões: a acumulação e a expansão, cujos excedentes de capital e força de trabalho podem pressionar determinada região, fazendo-a exportar capital e mão de obra (imigração ou migração, no caso de avanço para outras regiões de um mesmo país); revolução tecnológica, que aumenta a produção em intervalos cada vez mais curtos de tempo, mas que, por conseguinte, provoca o desemprego estrutural e tende a aniquilar empresas com baixo investimento em novas tecnologias; luta de classes, as quais podem forçar capitalistas e trabalhadores a migrarem para outros territórios, assim provocando o esvaziamento econômico da região; e ascensão do capital financeiro e das transnacionais, capazes de migrar para qualquer ponto do planeta de acordo com seus próprios interesses, dessa maneira afetando o próprio papel do Estado na economia em virtude do grande volume de capital que representam no contexto internacional. Em síntese, a plenária da indústria e comércio objetivava a adaptação das empresas a um novo ciclo de acumulação de capital, o neoliberalismo, por meio da defesa de uma coerência regional estrutural (Harvey, 2005, p. 150).

Segundo Harvey, a dinâmica do desenvolvimento do capitalismo é estruturada por um comportamento dialético que busca uma solução entre a continuidade da preservação de valores de compromissos passados (assumidos em um espaço e tempo específicos) ou a sua desvalorização (Harvey, 2005, p. 150), destarte depreendemos que essas lideranças empresariais do Rio de Janeiro almejavam a preservação de seus respectivos empreendimentos. Dessa forma, a plenária da indústria e comércio do Rio de Janeiro foi estrutura em painéis de discussão. Entre eles, destacamos os seguintes: desenvolvimento de complexos industriais; Rio de Janeiro - centro internacional de comércio e desenvolvimento tecnológico; Desenvolvimento do Rio de Janeiro como centro financeiro internacional; $\mathrm{O}$ Rio no contexto econômico e político empresarial. 


\section{O DESENVOLVIMENTO DE COMPLEXOS INDUSTRIAIS}

Do painel Desenvolvimento de complexos industriais, participaram José R. Nunes Firme, da ADEMI, como coordenador; José Augusto A. Brito, superintendente da AD-RIO, como expositor; Ricardo Lins de Barros², da Firjan e Luiz Geraldo Wately, da Ass. Com. de Resende, como debatedores; e Paulo Mário Freire, da Firjan, como relator. O referido painel tratava de anseios da indústria fluminense em toda cadeia de produção. O cerne da discussão, calcado por estudos realizados pela AD-RIO, estava em torno da criação de novos nichos de produção industrial que seriam açambarcados pela desconcentração espacial da indústria do estado do Rio de Janeiro, esta altamente concentrada na sua região metropolitana. Isso teria como desdobramentos a redução de custos da produção, o fortalecimento da economia estadual de forma mais heterogênea e articulada e a fixação da mão de obra qualificada no território do Rio de Janeiro.

O referido painel tratou de vários projetos, dentre os quais se destacavam a implantação de um complexo sideroquímico; uma montadora de veículos; um polo petroquímico; e um centro industrial portuário em Sepetiba. No que tange ao complexo sideroquímico a ser construído em Itaguaí, a AD-RIO e a Setepla Tecnometal ${ }^{3}$, promoveram um estudo em conjunto que tinha como conclusão a viabilidade econômica do investimento. Contudo, conforme expôs o relator e representante da Firjan, seriam necessários investimentos dos governos federal e estadual em infraestrutura para concretizar a instalação do complexo, como ampliação e modernização das vias férreas que ligavam Minas Gerais (local de onde viria a matéria-prima) ao Rio de Janeiro (neste caso, a região de Magé) e implantação da rodovia Itaguaí-Magé, responsabilidades federal e estadual, respectivamente. Notase, assim, uma articulação do processo produtivo desde a origem - com a obtenção da matéria prima no estado de Minas Gerais - até sua finalização, como produto acabado, a ser fornecido a indústrias no estado do Rio de Janeiro, num claro movimento de conexão inter indústrias.

Sobre a instalação de uma montadora de veículos no estado do Rio de Janeiro, o expositor citou o estudo em conjunto da Companhia Siderúrgica Nacional (CSN) e da AD-RIO, o qual recomendava a instalação de um parque automobilístico no estado do Rio de Janeiro. Entretanto, destacava que ele não deveria ser como em outros estados (São Paulo, Minas Gerais, Rio Grande do Sul e Paraná), cuja produção era de carros com baixo teor de tecnologia. Aproveitando as novas exigências dos consumidores, que ansiavam por carros cada vez mais modernos, o Rio de Janeiro, segundo o estudo, deveria aproveitar o seu expressivo parque de informática, natural embrião de um parque produtor de autopeças voltadas para informatização de bordo (Firjan, 1990, p. 10). Entendemos que o estudo traça a realização da produção de carros por meio de um novo nicho, até então não explorado em território nacional, fato que faria do Rio de Janeiro um novo polo de atração de investimentos ao passo do desenvolvimento de uma indústria de pujança tecnológica, cujos produtos teriam maior valor agregado.

O expositor destacou a mão de obra do Rio de Janeiro como a mais qualificada do país para esse tipo de empreendimento. Citou também que a possível localização da montadora seria no Vale do Paraíba (região próxima de São Paulo, localizada ao Sudoeste do Rio de Janeiro) ou próxima ao Complexo Industrial Portuário de Itaguaí, assim como a importância do apoio do governo federal por meio da revisão da Lei de Informática ${ }^{5}$, de forma a permitir a importação dos equipamentos para a essa indústria, e de uma política de nacionalização própria para este novo tipo de carro a ser produzido no país (Firjan, 1990, p. 10).

2 Era empresário da área petroquímica. Na década de 1990, ele presidia a Panamericana. Durante o mandato de Fernando Collor de Mello, foi convidado pelo então presidente da República a comandar a gigante estatal Petroquisa. Fonte: http://www.monitormercantil.com.br/index.php?pagina=Noticias \&Noticia $=133911$.

3 Criada em 1967, a Setepla oferece serviços na área de engenharia de projetos e assessoria técnica para empreendimentos nas áreas industriais, transportes, arquitetura/urbanização, meio-ambiente/saneamento e energia.

4 Devemos destacar que a CSN seria uma das principais fornecedoras de matéria prima para a montadora. A presença de um representante da cidade de Resende, no debate do painel, nos leva a crer na articulação de uma cadeia produtiva com redução de custos, tendo em vista a proximidade de Volta Redonda (localização da CSN) e Resende, e sua respectiva ligação por meio da Rodovia Presidente Dutra (BR-116).

5 Essa lei era de 1984, criava uma reserva de mercado para os fabricantes nacionais produtos de informática. Tal reserva propiciou a criação de mão de obra especializada no Brasil. Mas, ao final de 1991, ela foi extinta pelo governo Collor, assim abrindo o mercado para as empresas estrangeiras. Essa ação do governo foi ao encontro daquilo que foi expresso na v PLENINCo. Fonte: http://www. istoedinheiro.com.br/noticias/772_os+efeitos+colaterais+da+lei+de+informatica 
O projeto do Polo Petroquímico visava a integração deste com a economia fluminense, pelo fato de a matéria prima (gás natural e nafta) ser farta e disponível no território do Rio de Janeiro. Segundo o estudo realizado pela AD-RIO, os impactos nos campos econômico e social seriam um faturamento anual da ordem de 1,4 bilhão de dólares, a criação de 73.000 vagas de emprego e uma geração de impostos de cerca de 260 milhões de dólares. A implantação do polo, segundo o expositor, atrairia empreendimentos ligados ao setor de serviços e da indústria plástica, de têxteis, de detergentes, de tintas, de borracha e de bens de capital (Firjan, 1990, p. 13). Para realização do projeto, o governo federal deveria investir em infraestrutura, principalmente em energia e num terminal portuário.

A discussão sobre a construção de um polo petroquímico no estado começou ainda na década de 1980. Fez parte da campanha eleitoral do então governador Wellington Moreira Franco e era entendida com solução antirrecessão, além de assumir a perspectiva de tornar a indústria de produtos petroquímicos autossuficiente, passando o Brasil da condição de importador para a de exportador em alguns anos (Revista da Associação Comercial, 1988, nº 1240, p. 23). Em 1988, foi realizado um seminário promovido ACRJ para discutir a questão. Participaram a Firjan, a ACRJ, a Associação Brasileira da Indústria Química (ABIQUIM), empresários, autoridades (entre elas o governador do estado do Rio de Janeiro) e de técnicos ligados ao setor, como Paulo Belloti, presidente da Petroquisa ${ }^{6}$ à época. Em sua explanação, Belloti afirmou que a empresa estatal participaria como coordenadora da implantação do polo. Também participou do seminário Ricardo Lins de Barros, então presidente do Sindicato da Indústria Química do Rio de janeiro (sIQUIRJ), defendendo um modelo empresarial diverso do utilizado até então, no qual fosse contemplada a livre busca por novas tecnologias no processo de produção. Na sua concepção, o modelo tripartite (empresa estatal, capital privado nacional e investimento estrangeiro) adotado em outros polos petroquímicos, como o de Camaçari, na Bahia, tinha o grave problema de amarrar a tecnologia a apenas uma empresa multinacional (Revista da Associação Comercial, 1988, nº 1240, p. 22).

Retomando o debate do painel de discussão sobre complexos industriais, entendemos que Lins de Barros, naquele momento debatedor e representante da Firjan, tinha conhecimento de todo o processo para conceber o polo petroquímico no Rio de Janeiro, além de ter interesses imediatos, haja vista ser um empresário do ramo petroquímico. Ciente da importância de Lins de Barros no Rio de Janeiro, Collor o convidou para ser vice-presidente da Petroquisa. A estratégia do presidente da República parecia ser bem definida. Por um lado, deixava o processo de implementação do Polo nas mãos de um empresário ligado diretamente ao ramo de produção de produtos petroquímicos. Por outro, agradava todo um conjunto de empresários que iriam se beneficiar direta ou indiretamente com sua instalação no estado do Rio de Janeiro, desta forma angariando apoio político do $2^{\circ}$ estado mais rico da federação. É preciso salientar que o empresariado enxergava o Polo Petroquímico como solução para o esvaziamento econômico.

Outro tema debatido foi o projeto de construção do Centro Industrial Portuário de Sepetiba. Segundo o expositor, a infraestrutura tornou-se central na pesquisa da AD-RIO durante o levantamento de dados econômicos do Rio de Janeiro, pois ela determinaria os rumos a serem tomados no que tangenciava aos novos empreendimentos. O escopo traçado foi de uma produção industrial voltada para exportação, daí a importância da construção da ampliação do Porto de Itaguaí?. Argumentou-se que o crescimento econômico do estado estava limitado pelo da malha urbana, mas, em contrapartida, o Rio de Janeiro teria como induzir o avanço da economia por meio da utilização

\footnotetext{
6 Criada em 1967, a Petroquisa Química s.A. foi a primeira subsidiária da Petrobras com o objetivo de desenvolver e consolidar a indústria petroquímica no Brasil. Sua criação decorreu da impossibilidade tecnológica, empresarial e financeira da iniciativa privada, à época, de desenvolver a indústria petroquímica no país, assim como do desinteresse das grandes companhias estrangeiras em investir neste segmento, preferindo exportar produtos acabados de suas fábricas no exterior para o Brasil. Com a criação da Petroquisa, começaram a surgir as primeiras parcerias societárias mediante um modelo que ficou conhecido como tripartite, que estimulou a associação do Estado (por intermédio da Petroquisa), capitais privados nacionais e grupos internacionais detentores de tecnologia. Fonte: http://www.jorplast.com.br/jpdezo4/pago3.html.

7 Em 1973, o governo do então estado da Guanabara promoveu estudos para a implantação do Porto de Itaguaí, destinado a atender, principalmente, ao complexo industrial de Santa Cruz (RJ). Com a fusão dos estados da Guanabara e do Rio de Janeiro, em 15 de março de 1975, a implantação do porto ficou a cargo da Companhia Docas do Rio de Janeiro. As obras de construção do píer foram iniciadas em 1976, seguidas em 1977 pela dragagem, enroscamento e aterro hidráulico. O porto foi inaugurado em 7 de maio de 1982. Fonte: http://www.antaq.gov.br/Portal/pdf/Portos/Itaguai.pdf.
} 
da Baía de Sepetiba. Num raio de $500 \mathrm{Km}$ dessa região, estavam concentrados $32 \%$ da população do país, $65 \%$ do produto industrial, $65 \%$ dos serviços e $40 \%$ da produção agrícola (Firjan, 199o, p. 23).

Consoante o estudo da AD-RIO, a região possuía condições excepcionais. Suas águas são profundas, ideais para navios de grande porte, ao passo que possuía vasta extensão de terras contíguas interligadas ao município de Itaguaí, assim podendo formar um complexo industrial ao lado do porto. Outro argumento utilizado para ratificar a implantação do projeto, foi a localização em relação ao parque industrial no território nacional. A hinterlândia entre os portos de Paranaguá (localizado no estado do Paraná) e de Vitória (localizado no estado do Espírito Santo) abarcava a maior parte da produção industrial do país. Itaguaí estava localizada numa região de convergência das grandes estradas federais provenientes do Norte do Brasil, Mato Grosso, Minas Gerais, Brasília e São Paulo (Firjan, 1990, p. 22), fato relevante em relação a competitividade industrial, uma vez que seria possível realizar articulação de diferentes módulos de transporte, assim diminuindo o tempo de percurso dos insumos, commodities ou produtos industriais. A estimativa para um horizonte de 10 anos (neste caso especificamente, de 1990 a 1999) era de porto ter condições de exportar produtos petroquímicos e sólidos, produtos siderúrgicos, minério de ferro e grãos (Firjan, 199o, p. 26).

A conclusão do relator era de que a realização da ampliação do porto de Itaguaí só se daria com a mudança da legislação portuária, a qual era privativa da esfera de poder federal. Os empresários pleiteavam adequações para participação da iniciativa privada na concessão para administração e concessão do porto, além de modificações na forma de contratação da mão de obra (estivadores) (Firjan, 1990, p. 26).

Em visita ao Porto de Itaguaí, sete meses após a realização da v PLENINCO, o Secretário Nacional de Transportes, José Henrique D’Amorim Figueiredo, acompanhado do presidente da Companhia Docas do Rio de Janeiro (CDRJ), Celso Parisi, anunciou que o governo pretendera investir $300 \mathrm{mi}$ lhões de dólares entre os anos de 1992 e 1995. Esse montante representava cerca de um terço do custo total estimado para sua expansão (O Globo, 1990, p. 19).

Assim como no projeto do polo petroquímico, o governo Collor procurou estabelecer um diálogo salutar com os interesses dos empresários do estado Rio de Janeiro. A promessa de investimentos no estado serviria de contrapeso às ações orquestradas pelo governo no campo macroeconômico, como os Planos Collor I e II. O Presidente da República sabia do esvaziamento econômico pelo qual o Rio de Janeiro estava passando desde a década de 198o. Entendendo que o estado poderia fazer parte de sua estratégia política, que logicamente vislumbrava apoio de frações da classe dominante, Collor movimentou-se na direção dos interesses dos empresários do estado. Nomeou Ricardo Lins de Barros, importante empresário do Rio de Janeiro, vice-presidente da Petroquisa, sinalizando seu apoio à instalação do polo petroquímico no estado. No final da administração do governador Moreira Franco, propiciou o saneamento das contas do Banerj, importante banco para injeção de capital em obras de infraestrutura, além de liberar investimentos para pesquisas destinadas à produção de ciência e tecnologia por meio da realização empréstimos com bancos do exterior. Esta última temática foi debatida na v PLEninco. Chegou-se ao consenso de que empréstimos destinados a esse fim, embora aumentassem o déficit público, poderiam reduzi-lo a médio e longo prazo.

Esse conjunto de ações do governo demonstrava o desejo de que o apoio econômico do governo central ao Rio de Janeiro fosse revertido em apoio político a Collor. Durante seu governo, essa barganha com empresários fluminenses serviria de contrapeso às críticas de Mario Amato, presidente da Federação das Indústrias do Estado de São Paulo (Fiesp)

$\mathrm{Na}$ apresentação conclusão sobre o painel Desenvolvimento de Complexos Industriais, o relator, Paulo Mário Freire, representante da Firjan, dissera que, para ser competitivo no mercado externo, era preciso ter custos compatíveis com os de nível internacional. Fez consideração sobre a taxa de investimento no Brasil, explicitando que era uma das mais altas do mundo pela sua natural proteção à indústria nacional. Por fim, conclamou toda a sociedade a ajudar a solucionar os problemas do estado do Rio de Janeiro, por meio do apoio aos projetos ora apresentados e engajamento da classe política em prol dos objetivos apresentados na plenária (Firjan, 1990, p. 52). O discurso do empresário elucida o pano de fundo da V PLENINCA: nela estavam sendo orquestradas maneiras de atrair e fixar o capital no estado do Rio de Janeiro como forma de combater a recessão. A ideia de formação de complexos industriais no território estadual vai ao encontro do objetivo de tornar a indústria mais 
competitiva em relação à de outros países. Entretanto, não bastavam apenas os projetos e a disposição da classe empresarial para combater os problemas econômicos do estado, se fazia necessário o apoio político e econômico dos governos estadual e, principalmente, federal.

\section{O RIO DE JANEIRO COMO UM CENTRO INTERNACIONAL DE COMÉRCIO E DE DESENVOLVIMENTO TECNOLÓGICO}

Rio de Janeiro: Centro Internacional de Comércio e Desenvolvimento Tecnológico, esse foi o tema de mais um painel apresentado na plenária da indústria e comércio. Participaram representantes da ACRJ, AD-RIO, FCARJ, autoridades do estado do Rio de Janeiro, dentre elas o Secretário Estadual de Ciência e Tecnologia, José Pelúcio ${ }^{8}$, e representantes da Firjan. O painel tangenciou três temáticas: o Rio de Janeiro como centro internacional de comércio; a instalação de um teleporto; e a transformação do estado num centro de desenvolvimento tecnológico. A ideia central da discussão realizada no painel traz à tona o novo empreendedorismo. Como assinala Harvey, ele tem como pilar a noção de "parceria público-privada", na qual a iniciativa local se integra com poderes governamentais locais, buscando fontes externas de financiamento, novos investimentos diretos e novas fontes de emprego (Harvey, 2005, p. 172). Tal parceria entre governos locais e iniciativa privada tem o objetivo central de transformar uma cidade em um local de controle de funções de altas operações financeiras e de governo, além de transformá-la num centro de difusão e processamento informações.

Como forma de combater a instabilidade econômica, inerente às crises cada vez mais recorrentes do capital, e tornar o local mais competitivo, a colaboração público-privada dá ênfase a projetos estratégicos traçados a partir de uma lógica empresarial e especulativa, que tem como paradigma a busca por investimentos em serviços e a transformação da cidade em lugar de consumo em vez de a produção. Nessa nova dinâmica pró-capital, os gestores públicos têm o papel de atrair fontes externas de financiamento e novos investimentos diretos ou fontes geradoras de empregos por meio de subsídios, desonerações de impostos e oferta de infraestrutura, principalmente. Há o deslocamento do investimento público para atividades ligadas à reprodução do capital, dessa maneira ocorrendo o esvaziamento da função social do governo. Sendo a integração competitiva no mercado global o indicador de eficiência da gestão urbana.

No que toca a intenção de transformar o Rio de Janeiro num centro internacional de comércio, fica evidente que o empresariado tem noção das transformações no campo econômico-político-social e de seus desdobramentos em escala internacional. A centralização do processo decisório de investimentos alinharia o processo de acumulação de capital por meio de mecanismos de coordenação entre Estado e agentes privados. Assim, a intenção era de tornar a cidade uma organização totalmente estruturada, com o simples objetivo de receber investimentos, acréscimos econômicos e um desenvolvimento voltado apenas para a lucratividade e o bem do capital.

Consoante o entendimento dos expositores do painel, entre eles José Pelúcio, a presença dos países em desenvolvimento na economia internacional do futuro dependeria de vontade política para mobilizar seus próprios recursos de modo a otimizá-los sob a forma de produtos e serviços de valor adicionado (Firjan, 1990, p. 72). Nesse sentido, o Brasil deveria se estabelecer como elemento integrador e, concomitantemente, atuar como centro de mercado e finanças da América Latina.

Sob essa mesma ótica, o país também teria de rever e atualizar sua infraestrutura de comércio exterior, energia, transportes e recursos humanos, integrando-as com a visão moderna de comunicação e informação (Firjan, 1990, p. 75). Nessa conjuntura, a ACRJ afirmara acreditar que o Rio de Janeiro poderia dar uma contribuição decisiva na estratégia de desenvolvimento do país por meio da criação de um Centro Internacional de Comércio e Desenvolvimento Tecnológico.

Para tal objetivo, julgava-se imprescindível a ocupação ou recuperação de grandes áreas urbanas através de um plano integrado que articulasse as áreas de habitação, negócios, transportes, saneamento, energia e comunicações com toda uma estrutura especializada na prestação de serviços e no fomen-

8 No governo Moreira Franco, José Pelúcio Ferreira assumiu a recém-criada Secretaria de Ciência e Tecnologia do Estado do Rio de Janeiro. Sua principal realização, como secretário de Ciência e Tecnologia, foi a reativação da Fundação de Amparo à Pesquisa do Estado do Rio de Janeiro (Faperj). Fonte: http://www.canalciencia.ibict.br/notaveis/jose_pelucio_ferreira.html 
to às transações internacionais; a mobilização do governo, iniciativa privada e sociedade civil na busca por recursos; e atração de empresas nacionais e transnacionais com base na oferta de infraestrutura adequada (Firjan, 1990, p. 75). Sobre esta questão, as atividades ligadas às telecomunicações tornavamse centrais. Daí a intenção de se construir um teleporto na cidade do Rio de Janeiro (Firjan, 1990, p. 77), o qual iria viabilizar o exercício de controle e comando referentes às altas finanças, à coleta de informações e ao seu processamento. Isso de desdobraria em desenvolvimento de uma vasta gama de serviços de apoio, que poderiam coletar e processar informações rapidamente ou permitir consulta rápida a especialistas. Em síntese, significa transformar a localidade em exportadora de serviços (financeiros, informacionais e relativos à produção de conhecimento) (Harvey, 2005, p. 177).

No terceiro tópico abordado pelo painel, foram abordadas as questões que precisariam de apoio do governo federal, entre elas estavam: o pleito por uma política tecnológica; o aumento de recursos federais para a ciência e tecnologia; a instalação de um centro de pesquisa em microeletrônica através do CPqD ${ }^{9}$ da Telebrás em associação com universidades e empresas fluminenses; reequipamento e ampliação dos centros de pesquisa e laboratórios universitários federais instalados no estado; dar seguimento à implantação do Laboratório Nacional de Plasma e Fusão Nuclear Controlada; dotar a Universidade Federal Fluminense (UFF) de recursos para a implantação do Centro de Pesquisa em Biotecnologia Marinha; não colocar entraves ao endividamento externo do Estado que tenham o objetivo de captar recursos para investimento em ciência e tecnologia; criação de vantagens para empresas que investissem em pesquisa e desenvolvimento; fomento à criação de centros de pesquisa e laboratórios nas indústrias, entre outras (Firjan, 1990, p. 75).

O pleito por investimentos do governo central em ciência e tecnologia faz parte da estratégia da parceria público-privada, na medida em que o Estado participa de forma ativa na produção de conhecimento a ser difundido na iniciativa privada com vistas ao aumento da competitividade empresarial.

Esse leque de reivindicações do empresariado fluminense traz em seu bojo novas dimensões em pesquisa e de utilização de ciência e tecnologia, indutoras de reformulações produtivas e de uma nova configuração empresarial, que irão permear o comércio internacional, desdobrando-se numa reformatação política e administrativa dos Estados. A respeito deste ponto, René Armand Dreifuss afirma:

As colossais inovações científico-tecnológicas que marcam esta época viabilizam reestruturações dos sistemas produtivos e gerenciais, de alcance global, além induzir reorganizações cunho societário.

(Dreifuss, 1996, p. 33)

A afirmação supramencionada ratifica a ideia de revolução contínua da produção, pois o modo de produção capitalista não pode existir sem a revolução permanente dos meios de produção e da expropriação da mão de obra. Dessa forma podemos entender o capital como o motor de transformação em todos os campos da sociedade, na medida em que ele abala as condições sociais, tornando as relações antiquadas antes mesmo de elas se consolidarem (Marx; Engels, 1999, p. 29).

As transformações de cunho global operadas pela dinâmica do capital reverberavam no pleito dos empresários do Rio de Janeiro. Em harmonia com o discutido na v PLEnINCo, Collor, após sua posse, nomeia José Goldemberg, cientista renomado, para a Secretaria de Ciência e Tecnologia, que, ainda em maio de 1990, anunciou a negociação de dois empréstimos, um com Banco Interamericano de Desenvolvimento (BID) e outro com o Banco Mundial, cujos valores giravam em torno de 100 us\$ e 300 milhões de dólares, respectivamente. O repasse da verba seria realizado em cinco anos (O Globo, 1990, p. 19). Todavia, esse aporte de investimentos era de caráter suplementar, ou seja, estava suprindo a demanda que o orçamento do governo não suportou.

Existia também outro problema, o governo, por meio da reforma administrativa, reduziu em 30 $\%$ o quadro de funcionários da Financiadora de Estudos e Pesquisas (Finep) e extinguiu o Conselho de Ciência e Tecnologia, à época responsável pela distribuição das verbas na área científico-tecnológica, nas quais estavam inclusas as pastas dos ministérios da Saúde, Agricultura e Educação $(\mathrm{O}$

9 O Centro de Pesquisa e Desenvolvimento Padre Roberto Landell (CPqD) foi criado em 1976 na cidade de Campinas, estado de São Paulo. Tem como escopo o desenvolvimento de produtos eletrônicos para o ramo de telecomunicações. Fonte: http://www.telebras. com.br/inst/?page_id=41. Acessado em 24/04/2014 
Globo, 1990, p. 21). Esse corte de gastos, associado a empréstimos contratados junto a organizações internacionais de fomento, traça o perfil do que seria o governo Collor. Uma administração de caráter centralizador que optaria pela redução do estado em função da redução do déficit público. O controle mais concentrado do orçamento permitiria realizar investimentos de forma mais independente, facilitando seu direcionamento face aos seus interesses, não necessariamente econômicos, mas políticos. O ajuste na máquina administrativa daria fôlego às negociações junto à iniciativa privada, caracterizando uma "parceria" público-privada, na qual o estado catalisa fontes de financiamento por meio de seu próprio endividamento em função de uma lógica a partir de interesses empresariais.

Embora houvesse embaraços no orçamento destinado à pesquisa, ciência e tecnologia, o governo estava em consonância com alguns dos interesses explicitados na Plenária da Indústria e Comércio. Conforme previsto no Programa de Apoio ao Desenvolvimento Científico e Tecnológico II, os recursos para o desenvolvimento em pesquisa, ciência e tecnologia poderiam ser pleiteados por instituições públicas ou privadas, nas quais se incluíam universidades e centros de pesquisa. Podemos compreender, por meio de um raciocínio analógico, que boa parte do orçamento iria ao encontro dos interesses do Rio de Janeiro, pois em seu território estavam as universidades e os centros de pesquisa mais importantes do país organizados na chamada Rede de Tecnologia do Rio de Janeiro, cujo objetivo era o de atender às indústrias locais na demanda por desenvolvimentos experimentais, prestação de serviços técnicos, consultoria especializada e treinamento de pessoal (Firjan, 1990, p. 81).

\section{UM CENTRO FINANCEIRO INTERNACIONAL NO RIO DE JANEIRO}

A desregulação do mercado de capitais também foi tema de discussão na v PLENINCo. No painel "Rio de Janeiro como centro financeiro internacional", houve a explanação de como integrar o Brasil ao mercado financeiro internacional de forma a angariar investimentos, escassos durante a década de 1980. Participaram das discussões representantes da BVRJ, Andima, Ibef e do governo do estado do Rio de Janeiro. Embora a Firjan não tenha participado de forma direta nesse painel, os interesses da indústria se faziam presentes por meio do secretário estadual de indústria e Comércio, Rodrigo Paulo de Pádua Lopes, que havia sido presidente da Companhia do Polo Petroquímico do Rio de Janeiro $^{10}$ e da empresa multinacional Hanna Minning, cuja atuação era exercida nos setores de mineração e, principalmente, no petroquímico.

A chave para o entendimento do desenvolvimento econômico, segundo os preceitos da globalização, era a adoção de mercados livres e do dinheiro saudável. Nessa esteira, o capital das empresas não deve mais estar atrelado somente ao capital nacional devido às novas estratégias orquestradas pelos players globais. Dada a conjuntura, o capital busca por ambientes onde exista credibilidade para o seu desenvolvimento e, concomitantemente, as empresas devem criar novas formas de organização, vislumbrando uma concorrência mais agressiva e os mercados financeiros. Isso gera a intensificação e a mundialização da concorrência em estreita articulação com a face financeira do capital, visto o peso das transformações tecnológicas. Sobre a questão, Karl Marx sintetiza o cerne da expansão do capital:

(...) a finalidade direta a que o processo de produção capitalista se propõe, já que o capital quer produzir capital... não é nem diretamente um valor de uso para o próprio consumo, nem uma mercadoria a ser convertida, primeiramente em dinheiro e mais tarde em valor de uso. A finalidade deste processo - é outra, é o enriquecimento, a valorização do valor, sua expansão. (Marx apud Garllip, 2006, p. 2)

As transformações proporcionadas pela economia desregrada impactam de forma incisiva o Estado Nacional, na medida em que reduzem seu papel na economia. O papel principal nessa conjuntura passa a ser exercido pelo capital financeiro globalizado, que reorganiza o sistema financeiro global e concen-

10 Criada em 1987 pelo governo do estado, a COPPERJ tinha a finalidade de promover a localização e prover a infraestrutura básica do Polo Petroquímico do Rio de Janeiro, especialmente no que diz respeito às necessidades de transporte, energia, telecomunicações, saneamento, abastecimento de água e apoio social.Fonte: http://alerjln1.alerj.rj.gov.br/contlei.nsf/bcoo8ecb13dcfc6eo3256827006dbbf5/ 18ocreb5eed4ca5do32565410063C53e?OpenDocument. Acessado em 17/04/2014. 
tra o poder nas mãos de conglomerados transnacionais. Produz-se, destarte, uma nova forma de dependência que extravasa o poder das nações até mesmo dos países centrais. Todos os interesses devem resignar-se aos do núcleo orgânico do capital (Garlipp, 2006, p. 4), o que forçaria os países da periferia a adaptar-se, abrindo seus mercados e fazendo ajustes macroeconômicos. Celso Furtado reforça esse argumento: "A doutrina corrente nos apresenta a globalização como imperativo tecnológico, portanto, inescapável para as economias que aspiram a desenvolver-se" (Furtado, 1999, p. 221).

Esse cenário de mudanças na conjuntura internacional serviu de argumento à intenção de transformar o Rio de Janeiro em um grande centro financeiro internacional. A linha de argumentação apresentada no painel utilizou a abertura da economia da União Soviética como exemplo. Segundo o exposto, a pressão da globalização foi tão intensa que provocou a integração competitiva desse país, mesmo com uma longa tradição isolacionista de seu Politburo (Comitê Central do Partido Comunista Soviético). Outro argumento apresentado foi o fato de a integração ao mercado internacional facilitar a captação de recursos a um baixo custo para as empresas e permitir a administração de sua exposição a um risco cambial e financeiro, à época não proporcionada pela legislação vigente. Após a argumentação, os expositores do painel sugeriram quatro alternativas para implementação do centro financeiro, a saber: 1) criação de um centro off-shore restrito; 2) criação de um centro off-shore convencional; 3) criação de um centro off-shore integrado; 4) criação de um centro off-shore integrado e acoplado aos demais mercados (Firjan, 1990, p. 89).

A ideia de funcionamento do centro off-shore restrito consistira em operações financeiras a serem realizadas por bancos brasileiros no exterior. Isso permitiria aos bancos fazerem transações em moeda estrangeira dentro do território nacional após captação de recursos no exterior. A segunda alternativa, centro off-shore convencional, ampliara as concepções adotadas na primeira alternativa. Nesse tipo de centro financeiro, os bancos estrangeiros teriam permissão para fazer operações com moeda estrangeira em território nacional. Já a terceira alternativa, centro off-shore integrado, o capital em forma de moeda estrangeira poderia entrar e sair do país de acordo com os interesses das instituições financeiras. A quarta e última, centro off-shore integrado e acoplado, amplia todas as alternativas anteriores. Sua proposta era não somente a liberação de transações financeiras em moeda estrangeira no território nacional, mas também a abertura da Bolsa de Valores e de Futuros a investidores estrangeiros.

O painel destacou a Bolsa Brasileira de Futuros como importante para o país devido ao fato de o Brasil ter vocação agrícola. Assim, suas commodities poderiam ser alvo de um grande volume de investimentos (Firjan, 1990, p. 93). Segundo o documento apresentado na plenária, além de estabelecer a integração competitiva com o mercado internacional, a implementação do Centro Financeiro Internacional na cidade do Rio de janeiro conteria o esvaziamento econômico da cidade e, por conseguinte, do estado. Conforme análise apresentada, a renda interna global, no período entre $1970 \mathrm{e}$ 1980, teve incremento em níveis mais baixos que os dos estados de São Paulo, Minas Gerais e Rio Grande do Sul. Isso se refletiu numa taxa anual de crescimento industrial mais baixa em relação a esses estados e na redução do número de bancos presentes no estado (Firjan, 1990, p. 95).

No que tange às conclusões do painel, era consenso a integração da economia brasileira à internacional. Os expositores expressavam que não fazia sentido o Brasil importar $4 \%$ do seu PIB (produto interno bruto) e participar apenas de $1 \%$ do volume do comércio internacional. E que a integração do país com o comércio físico internacional deveria ser estruturada pela abertura do mercado financeiro, fato este que viabilizaria a dinamização da administração financeira das empresas brasileiras competitivas (Firjan, 1990, p. 96). O desejo deste grupo de empresários só seria possível com a mudança da legislação cambial, que deveria tornar o câmbio flutuante, permitindo transações em moeda estrangeira no território nacional. Esse pleito foi atendido por Collor durante a implementação do Plano Collor I.

Importa aqui destacar o pronunciamento do representante do governo do estado do Rio de Janeiro no painel, Rodrigo Lopes. Segundo ele, o projeto de integração competitiva do Brasil ao mercado financeiro internacional deveria ser realizado em sua forma mais restrita, em virtude das dificuldades da mudança no ordenamento jurídico vigente. Entretanto, julgou oportuno apresentar todo o projeto de criação de um Centro financeiro internacional na cidade do Rio de Janeiro (Firjan, 1990, p. 97).

Entendemos, portanto, que o projeto proposto tem sua gênese na identificação pormenorizada do processo de globalização e de suas benesses para o grupo empresarial presente na plenária. Temas 
como esvaziamento econômico, desemprego e violência serviram à retórica de abertura de mercado, tanto financeiro, quanto comercial. Não obstante a essa argumentação, é possível depreender que o cerne da preocupação dos empresários era a falta de capital disponível para investimento, o que seria suprido por recursos privados vindos do exterior. Esse desejo dialoga com a análise de Furtado:

A tendência à subutilização do capital explica a grande disponibilidade de recursos líquidos para investimento no exterior, o que está na raiz da globalização. Com efeito, esta resulta da ação conjugada de dois vetores: o esforço da oferta de recursos para investir no exterior, que se observa nos países de capitalismo avançado, e a orientação dada a esse processo pelas empresas transnacionais.

(Furtado, 1999, p. 14)

\section{O RIO NO CONTEXTO ECONÔMICO E POLÍTICO EMPRESARIAL}

O quinto e último painel da Plenária da Indústria e Comércio, "O Rio no contexto econômico e político empresarial", teve como coordenadores os presidentes das entidades patrocinadoras do evento, como expositores Amaury Temporal, vice-presidente do Cirj, e Ney R. Ottoni de Brito, representante da ACRJ e do Ibef e coordenador da v PLENINCO junto com Georges Barrene da Firjan, que marcou presença no painel sendo o moderador. O debate girou em torno da ação política do empresariado no ano de 1990, que seria marcado pela assunção de um presidente eleito pelo voto popular após vinte e cinco anos.

Em pronunciamento, Ney de Brito delineou aspectos econômicos presentes no país e tracejou uma perspectiva sobre o governo eleito. O expositor do painel afirmou que o estado encontrava-se desajustado, absorvendo de $85 \%$ a $90 \%$ da poupança financeira gerada pela sociedade, e fez comparações entre o Brasil, cuja participação na economia era de $2 / 3$ do capital e $1 / 3$ dos salários, e países socialmente estáveis, nos quais esta proporção era inversa, desta forma ratificando a ideia de grande desequilíbrio na distribuição social da renda (Firjan, 1990, p. 105). Esta é uma questão-chave que vai perdurar durante todo o governo Collor. O aumento da participação dos salários no PIB era condição sine qua non para o desenvolvimento sustentável da economia, avolumando o mercado interno e aumentando os índices de produtividade, desta maneira diminuindo a participação do capital no PIB. Após longo processo de acumulação intensiva de capital, à custa de uma parca distribuição de renda durante a ditadura militar, já era evidente, a partir da década de 1980, que esse ciclo econômico estava exaurido. Fazia-se necessário o reescalonamento da participação da massa salarial na economia. No cálculo da classe empresarial, o aumento da renda era um dos fatores que melhorariam o quadro econômico brasileiro.

Ney de Brito também reconheceu que o governo eleito deveria fazer ajustes estruturais que circunscreviam ajustes de caixa, aumento de impostos e corte de despesas. Porém ressaltava que as mudanças deveriam ser pactuadas com o estrato social e a classe empresarial, sendo o empresariado fluminense a interface entre o governo e a comunidade do Rio de Janeiro. Para tal participação no processo de negociações, sugeriu duas medidas: a criação de um centro de ação política no estado do Rio de Janeiro, que deveria ser o braço intelectual, o cérebro pensante que coordenaria e direcionaria a ação empresarial; e a pulverização da ação empresarial por meio da criação de redes de comunidades empresariais de base em nível regional. Sustentou também a ideia que os empresários deveriam manter um relacionamento constante e regular com os políticos fluminenses, e não apenas monitorar seus desempenhos (Firjan, 1990, p. 107), denotando uma nova forma de atuação junto à classe política, a qual consistia no acompanhamento de todo o trâmite legislativo.

Amaury Temporal julgou oportuno enfatizar duas opções de ação política empresarial. A primeira seria a pressão de "pé de ouvido", que segundo ele sempre ocorrera no Brasil, no entanto sua eficácia só se verifica nos resultados finais. Já a segunda, consistiria na participação no processo decisório, de forma competente, organizada e permanente, com base programática explícita e definida (Firjan, 1990, p. 105). Em sua concepção, a última deveria ser adotada.

O presidente da Firjan, Artur João Donato, disse acreditar que a solução para os problemas do Rio de Janeiro era de caráter eminentemente político. Para ele, os empresários deveriam esforçar-se politicamente para garantir sua própria expansão. A consciência regionalista, em seu entendimento, refletiria em benefícios em prol do estado e da cidade do Rio de Janeiro, mas para alcançá-los seria 
importante o apoio da representação política. O entrosamento com parlamentares tornaria possível o direcionamento de decisões em favor da classe empresarial, contudo destacou a importância da participação de outros segmentos como trabalhadores, administradores e intelectuais. Donato entendera que a estruturação da ação política seria ter a PLENINCo suprida tecnicamente e ter o "cérebro pensante" suportando as atividades das comunidades empresariais de base, em nível municipal e local. Essa conjuntura provocaria a aglutinação dos empresários em torno da plenária, o que se desdobraria em formulações e diretrizes gerais para as classes produtoras sem prejuízo de, individualmente, defenderem seus interesses setoriais ou regionais (Firjan, 1990, p. 108).

O representante da Associação Comercial de Resende, Luiz Geraldo Wately, entendia que ineficiência do governo decorrera da falta de cobrança mais ativa por parte dos empresários. Como resolução para esse problema, indicou a possibilidade de a orientação técnica ser exercida por um "cérebro pensante" - o Instituto Mauá ${ }^{11}$ - o qual faria com que a ação política empresarial fosse constante e organizada. Apresentou como sugestão o exercício da prática política por meio de um partido, podendo a participação ser realizada a partir de candidatura, colaboração ou afiliação ativa. Ainda discorrendo sobre a temática, Ricardo Degenszejn afirmara que o empresariado não acompanhara de forma sistemática o desempenho político, diferentemente de países desenvolvidos, onde questões de interesse do setor tinham a participação constante e metódica da classe (Firjan, 1990, p. 106).

A prática política do empresariado para o presidente da Associação Comercial do Rio de Janeiro, Paulo Protásio, era muito precária e deveria ser revertida rapidamente. Ele propusera a divulgação de informações de maneira sistemática sobre potencialidades e desempenho de políticos candidatos à reeleição, um calendário de ação política e o fortalecimento do Instituto Mauá. Assim configurando um novo tipo de metodologia de ação empresarial, no qual o pleito de interesses junto à classe política deveria vir assistido de estudos prévios, de múltiplas questões, eleitas conforme a necessidade e demanda do setor empresarial.

Curiosamente colocado às primeiras páginas do documento-resumo da plenária, o registro de encerramento da V PLENINCO sintetiza o propósito pactuado entre as instituições de representação empresarial presentes, o de uma ação política próxima do poder legislativo:

O empresariado fluminense quer fortalecer sua atuação política, através do apoio a candidatos que defendam os interesses da economia do estado ou da candidatura de empresários nas eleições deste ano para o Congresso Nacional. Essa ação política, porém, não pode parar numa eleição, que é realizada a cada quatro anos. Ela deve ser permanente, através de uma postura mais contundente e adequada à posição que o estado do Rio de janeiro ocupa no cenário econômico e político nacional. Em suma: o estado precisa ter voz mais ativa e posição de maior destaque nos meios políticos da Nação. Com este objetivo, o empresariado fluminense resolveu cerrar fileiras e trabalhar com dedicação. A luta está, apenas, começando, mas já se vislumbram resultados compensadores. $\mathrm{O}$ consenso obtido na V PLENinCo é o primeiro resultado promissor. (Firjan, 199o, p. 6)

\section{CONSIDERAÇÕES FINAIS}

Com a vitória de seu candidato na eleição de 1989, o empresariado tinha expectativas positivas para o ano de 199o. Esperava-se que o novo governo resolvesse os problemas macroeconômicos do país, tirando-o da recessão, embora soubessem dos sacrifícios a serem realizados para a conquista da estabilidade econômica. Figura de grande expressão, Artur João Donato, presidente da Firjan, saiu em defesa da retomada do desenvolvimento econômico em nível regional e nacional. Para a Firjan, era momento de alavancar a economia do estado por meio da formação de um mercado interno no país.

A v PLENINCo teve como pano de fundo o estabelecimento de um consenso, recorrente na retórica de Donato. O empresariado fluminense dotado de instrumentos financeiros e intelectuais traçou uma estratégia de defesa da coerência estruturada da região do estado do Rio de Janeiro, já que um novo

11 Braço intelectual da Associação Comercial do Rio de Janeiro. 
ciclo de acumulação de capital espremia a economia brasileira forçando-a a se adaptar às transformações de escala mundial. Essa era a única maneira de a ordem capitalista nacional manter seu status quo.

É interessante destacar que a reunião plenária da indústria e comércio teve como participante um banco estatal, o Banerj, o que denota o interesse de empréstimos subsidiados para consecução dos projetos apresentados pela AD-RIO. A mudança de padrão de acumulação de capital configurou um novo empreendedorismo, o qual foi operacionalizado por meio de uma parceria público-privada. O estado faria investimentos a partir de uma lógica empresarial, pautada em preceitos de competitividade.

Como faces da mesma moeda estavam, de um lado, a necessidade investimentos externos para o aumento da produção e consequente aumento de competitividade em nível global; e do outro, a abertura do mercado de capitais que poderia deteriorar a economia nacional por meio da especulação do capital fictício. Nesse sentido, o modus operandi dos empresários foi pautado pelo pleito da adoção de uma espécie de híbrido, o qual abarcava preceitos neoliberais mais a participação do Estado em questões de cunho financeiro em favor do capital nacional. Desta forma, como citado anteriormente, o governo Collor procurou investir, ainda de forma indireta, no estado do Rio de Janeiro por meio de projetos voltados para pesquisa, ciência e tecnologia, do saneamento do Banerj, e até mesmo, através da liberação de linhas de crédito via BNDES, nos casos de comprometimento de contenção de despesas do governo estadual, como aconteceria durante a gestão de Brizola.

Os projetos e proposições da $\mathrm{V}$ PLENINCO foram ao encontro do ideário neoliberal, na medida em que objetiva o aumento dos níveis de competitividade da indústria e apoiavam a abertura da economia. Isso significa que os empresários do Rio de Janeiro queriam a inserção do Brasil no mercado global com vistas à realização de acumulação de capital extrafronteira nacional e obtenção de investimentos externos. Para tanto, deveriam concorrer com seus pares de outros países. Esse é o ponto no qual se insere a ideia conservação da burguesia interna organizada. A defesa de seu status quo e sua sobrevivência no campo econômico deveriam se dar, em sua concepção, a partir do apoio estatal, travestido de parceria público-privada, sendo revertido em subsídios, isenção de impostos, empréstimos de bancos estatais e investimentos em infraestrutura. Esse conjunto facilitaria a constituição de complexos industriais e criaria novos nichos de produção, tendo como desdobramentos o aumento da competitividade industrial e o aumento do valor agregado da produção, desta maneira aumentando as taxas de lucro.

O Polo Petroquímico fora assunto recorrente no final da década de 1980 e fez parte da pauta da plenária. Sua instalação era vista, por políticos e empresários fluminenses, como solução para o esvaziamento econômico, pois desencadearia o estímulo à produção de todo um segmento industrial e, indiretamente, reaqueceria setores como o da construção civil, que seria responsável pela implementação da infraestrutura, além de criar empregos no setor de serviços. Nesse ponto, Collor atendeu ao maior anseio do estado nomeando Lins de Barros como vice-presidente da Petroquisa. Ainda em consonância com a entrada de capital no estado, grande parte dos investimentos da Secretaria de Ciência e Tecnologia foi destinada ao Rio de Janeiro de forma indireta. Cabia às instituições de pesquisa e universidades públicas elaborarem projetos conforme o delineamento do governo. O estado angariou boa parte do aporte financeiro por deter um grande número dessas organizações em seu território. Toda essa conjuntura contemplou objetivos traçados na V PLENINCo.

A plenária também tracejou uma nova forma de ação política do empresariado fluminense. Ficou acordado durante a plenária, que a melhor estratégia seria acompanhar de perto os projetos de interesse do Rio de Janeiro no Parlamento, e também sistematizar uma participação política mais ativa, por meio de filiação a partido político e, até mesmo, candidatura a cargos do executivo e legislativo. Os ares da transição democrática fizeram os empresários perceberem que a "política do pé do ouvido", cujo objetivo era pleitear benesses diretamente a um Secretário de Estado ou Ministro de Estado, não teria mais serventia diante da ampliação dos participantes no processo político decisório. $\mathrm{O}$ funcionamento das instituições (aqui frisamos as de cunho legislativo) daria outra dimensão aos processos de negociação. Nesse aspecto, os empresários do estado do Rio de Janeiro decidiram participar de forma mais incisiva no processo decisório, ampliando sua participação no âmbito do poder legislativo, traçando alianças com o poder executivo, como no caso do governador Leonel Brizola em 1991, e apoiando Collor na sua política macroeconômica.

Entendemos o alinhamento de Collor com os anseios do empresariado fluminense como pontochave para manutenção de sua governabilidade. Na medida em que o novo presidente da República 
fazia planos de investimentos no estado, tornava a classe política fluminense e seu empresariado aliados, ainda que de ocasião. Vale ressaltar que Lula obteve mais votos que Collor no Rio de Janeiro, o que não tornava a região um ponto de apoio político ao governo, a princípio. Quando o novo governo passa interagir de forma mais dinâmica com os interesses do estado, cria uma relação de simbiose. Embora fosse de cunho altamente centralizador, o que não agradara ao empresariado, Collor lançou mão da barganha para sustentá-lo no poder. A estratégia perduraria até setembro de 1992, quando ocorreu a abertura do processo de impeachment.

\section{BIBLIOGRAFIA}

BELLUZZO, Luiz Gonzaga. Finança global e ciclos de expansão. In: Estados e moedas no desenvolvimento das nações. Rio de Janeiro: Editora Vozes, 2012.

CARNEIRO, Ricardo. Desenvolvimento em crise: a economia brasileira no último quarto do século XX. São Paulo: Editora Unesp, 2002.

DINIZ, Eli. Globalização, Reformas Econômicas e Elites Empresariais. Rio de Janeiro: FGV, 2000. . Eli. O pós-Consenso de Washington: globalização, Estado e governabilidade reexaminados. In: Globalização, estado e desenvolvimento: dilemas do Brasil no novo milênio. Rio de Janeiro: FGV, 2007. . \& BOSCHI, Renato. Lideranças empresariais e problemas de estratégia liberal no Brasil. XVI Encontro Anual da ANPOCS, Minas Gerais, 1992.

DREIFUSS, René Armand. A Época das Perplexidades. Rio de Janeiro: Vozes, 1996.

FURTADO, Celso. O Longo Amanhecer Reflexões sobre a Formação do Brasil. São Paulo: Editora Paz e Terra, 1999.

GARLIPP, José Rubens Damas. Marx, Keynes e Polanyi e a economia desregrada. Três contribuições críticas ao mercado auto-regulado" Rio de Janeiro.: Anpec, 2006.

HARVEY, David. A Produção Capitalista do Espaço. São Paulo: Annablume, 2005.

LEOPOLDI, Maria Antonieta Leopoldi. Política e Interesses na Industrialização Brasileira: As Associações Industriais, a Política Econômica e o Estado. São Paulo, Editora Paz e Terra, 2000.

LOURENÇO NETO, Sydenham. Muito além do petróleo: O fim de Bretton Woods e a crise dos anos 70. Revista História e Luta de Classes. 2013. № 16.

MARX, K.; ENGELS, F. Manifesto do Partido Comunista. 9. ed. Petrópolis, Rio de Janeiro: Vozes, 1999. Teorias sobre la plusvalia. Apud GARLIPP, José Rubens Damas. Marx, Keynes e

Polanyi e a economia desregrada. Três contribuições críticas ao mercado auto-regulado". Rio de Janeiro: Anpec, 2006.

SALLUM JÚNIOR, Brasílio. "Metamorfoses do Estado Brasileiro no início do século XX". In; revista Brasileira de Ciências Sociais. Vol. 18, nº 52, junho. 2003.

VIANNA, Luiz Werneck. De um Plano Collor a Outro. Rio de Janeiro: Ed Revan, 1991.

\section{Fontes primárias}

V PLENINCO. FIRJAN RJ. 1990.

Revista da Associação Comercial, 1988, n 1240

O Globo. Caderno de Economia/negócios. 27/08/1990. p 19.

O Globo. Caderno O Mundo/Ciência e Vida. 11/05/1990. p. 19.

O Globo. Caderno Ciência e Vida. 20/o6/199o. p. 21.

\section{Sites}

http://www.aafbanerj.org.br/home_memoria.asp. Acessado em 14/o4/2014. http://www.adrio.org.br/site/empresa.php. Acessado em 14/o4/2014.

http://alerjln1.alerj.rj.gov.br/contlei.nsf/

bcoo8ecb13dcfc6eo3256827006 dbbf5/18oc1eb5eed 4ca5do32565410063c53e?OpenDocument.

Acessado em 17/04/2014.

http://www.antaq.gov.br/Portal/pdf/Portos/Itaguai.pdf. Acessado em 21/04/2014.

http://www.canalciencia.ibict.br/notaveis/jose_pelucio_ferreira.html. Acessado em 21/04/2015 
http://www.foregon.com/glossario/104/andima.aspx. Acessado em 14/04/2014.

http://www.ibefrio.org.br/secoes/page/4/Historia. Acessado em 14/04/2014.

http://www.istoedinheiro.com.br/noticias/772_os+efeitos+colaterais+da+lei+de+informatica.

Acessado em 15/04/2014.

http://www.jorplast.com.br/jpdezo4/pago3.html, acessado em 19/04/2014.

http://www.monitormercantil.com.br/index.php?pagina=Noticias\&Noticia=133911. Acessado em $15 / 04 / 2014$.

http://www.telebras.com.br/inst/?page_id=41. Acessado em 24/04/2014. 